\title{
SOZECOM: Leveraging the Synergy between the Existing Structure and Opportunities in Digital Finance
}

\author{
Muhammad Lawal Maidoki \\ Sokoto State Zakat and Waqf (Endowment) Commission, Sokoto, Nigeria \\ Paper to be presented at International Conference of Zakat 2018 \\ 15-16 November, Universitas Gadjah Mada, Yogyakarta, Indonesia
}

\section{ABSTRACT}

Sokoto State having a land mass of 25,973 $\mathrm{km}^{2}$ and located in Northwestern Nigeria has a population of about 5.7 million people. Over $80 \%$ of the people are farmers living predominantly in the rural areas. As a consequence of this they are both financially and digitally excluded from participating in the formal and increasingly digitalized global economy. Sokoto State Zakat and Waqf (Endowment) Commission (SOZECOM) Nigeria aims to drastically reduce the widespread prevalence of poverty in the state. SOZECOM utilizes an extensive network of volunteers covering all the districts in the state. Almost 50\% of the rural population own or have access to mobile phones. By using this network and the access to mobile phones, SOZECOM aims to bridge the gap in financial services between the mostly rural areas and the urban centre through the development of a framework involving the use of volunteers as agents. This will greatly assist in the collection, management and distribution of both zakat and waqf funds. This paper presents the activities undertaken, for greater rural financial inclusivity and participation in the digital economy, the opportunity and constraints.

Keywords: SOZECOM, Financial inclusion, Agent network, Rural Access.

\section{INTRODUCTION}

Balancing financial sustainability with organizational mission is a core challenge for most nonprofits. The digital age is changing our lives - socially, economically and politically. About 2 billion adults, $70 \%$ of people in developing countries, do not have access to formal financial services [1]. In 2012, Nigeria signed the Maya Declaration, committing to reducing financial exclusion to 20 percent by 2020.In the realm of development cooperation, digital technologies offer a chance to tap completely new opportunities and to bring about structural change of a new quality. Modern information and communication technologies (ICT) can help make processes more efficient, quicker, and more cost-effective. ICT can link people who would usually not come into contact with each other. Solutions can emerge that previously seemed unthinkable [2].

To participate in the digital future, we have to take account of these aspects and also be open for new ways of thinking to arrive at solutions, for new forms of cooperation, and for new partnerships. To foster sustainable digital development we broaden people's access to internet and phone networks, reinforce cooperation with young people and new partners and strengthen digital skills [1]. In Nigeria smallholder farmers face tremendous challenges in improving their livelihoods, including limited or no access to valuecreating services and resources and branchless banking. Digital or mobile finance technologies using mobile money platforms have demonstrated the potential to unlock some of that lost value. role that digital finance can play in providing a more cost-effective and secure method for financial transactions in the agricultural 
sector, particularly for rural smallholder farms. Increasing access to agri-digital finance not only creates new market opportunities for business, but also provides a vital service to smallholder farmers [2].

\section{Benefits of Digital Finance}

Digital finance promotes financial inclusion More than 2 billion people have no access to any financial services. Overall, only about 59 percent of men and 50 percent of women in developing countries have an account at a regulated financial institution. Women, the poor, and small businesses often rely on informal financial services, even when they receive public transfers or remittances [3]. Digital payment systems help overcome barriers to accessing financial services. Mobile money schemes, in particular, allow people who own a phone but do not have a bank account to make and receive payments. In the right environment, these systems can take off and reach massive size rapidly recognizing the potential of inclusive finance for meeting objectives such as those embodied in the Sustainable Development Goals, financial inclusion has become a priority for policymakers, regulators, and development agencies alike. As the figures suggest, the world continues to struggle to ensure poor households can access to formal financial services. In this context, digital financial technology is spurring new optimism by providing accessible and affordable digital financial services to unbanked populations, especially poor and low-income households. Given these challenges, there is a more determined policy push for digital financial services as a means to accelerate financial inclusion for the poor, bypassing the challenges presented by traditional financial services channels [3].

\section{Study Area}

The immediate area of Sozecom's operation is Sokoto State but because in most cases humanitarian need transcends geography, we also are increasingly engaged beyond Sokoto State and Nigeria. Sokoto State $\left(13^{\circ} 05^{\prime} \mathrm{N}, 05^{\circ} 15^{\prime} \mathrm{E}\right)$, located in Northwestern Nigeria has a population of about 5.7 million people predominantly $(80 \%)$ engaged in farming as primary occupation. The state covers a total of about $26,000 \mathrm{~km}^{2}$ and shares borders in the north with the Republic of Niger, to the east with Zamfara State and with Kebbi State to the southwest. It comprises 23 Local Government Areas and 86 districts.

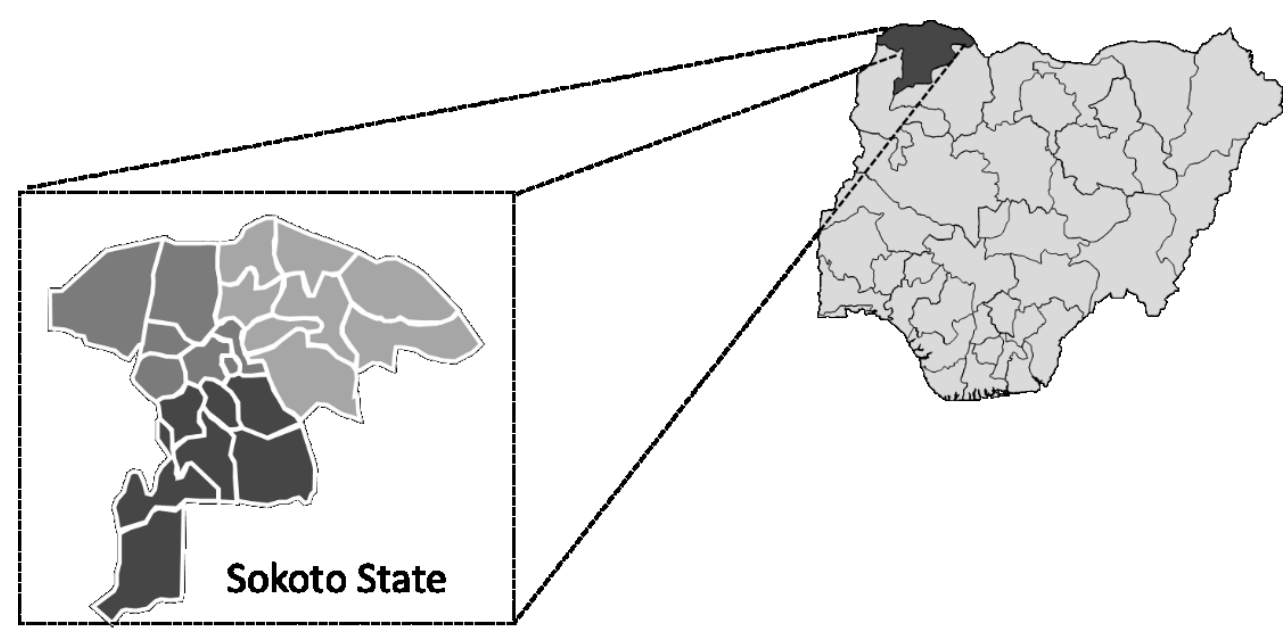

Figure 1. Location of Sokoto State 
The State is endowed with abundant agricultural and natural resources which, if exploited can pave the way for industrial development in the State. The economic potential of both the agricultural and solid mineral sub-sector has remained largely untapped over the years. Sorghum, millet, maize, wheat, rice, cowpea, sugarcane, gum arabic, sweet potatoes, cassava, neem seeds, kenaf, pepper, mango, cashew nut, locust beans, ground nut, tomatoes, garlic, onions, spices, acacia nilotica, tamarind, castor seed, sesame seed, sheep, cattle, goat, hides and skin, fisheries are some of the state's agricultural potentials. There are an estimated 15 million heads of livestock including cattle, camel, sheep and goats making the state the second largest in Nigeria with regard to livestock production.

Inspite of this potential, however, the rural population remain largely poor in most cases unable to meet their bare necesities. This is as a result of a variety of factors. The pattern of land ownership is characterized by fragmentation with the average family owning less than a hectare. Few arable crops essentially dominate farming activities.

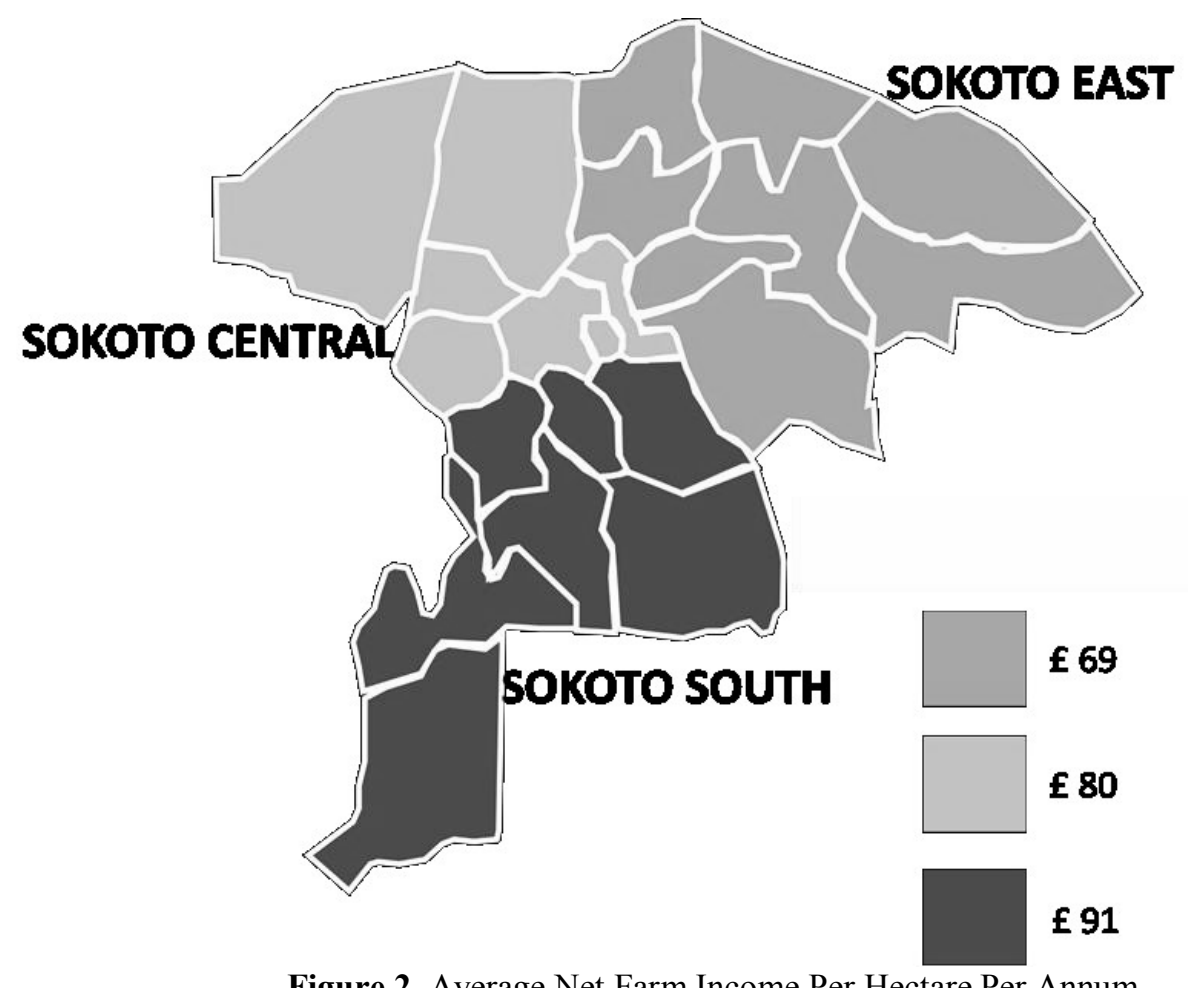

Figure 2. Average Net Farm Income Per Hectare Per Annum

Like most places in the region, Sokoto state is also particularly subject to environmental degradation. Land, water and soil fertility have been seriously depleted as a result of intensive cropping and overgrazing, and droughts have become increasingly common occurrences in the area. Since most of the rural population practices subsistence farming, the decline of the resource base brings extremely low yield, chronic food shortages and greater poverty. Net farm income is less than $£ 100$ per hectare per year. 


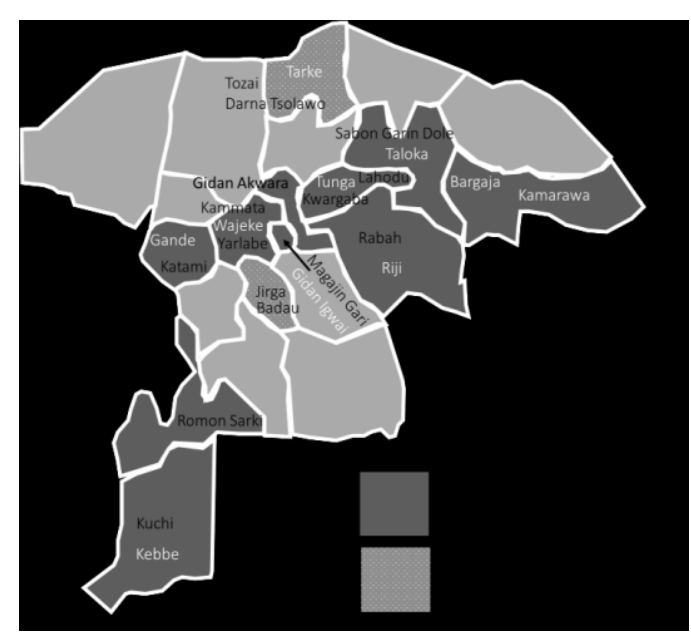

Figure 3. Perennial Drought and Flood Hotspots
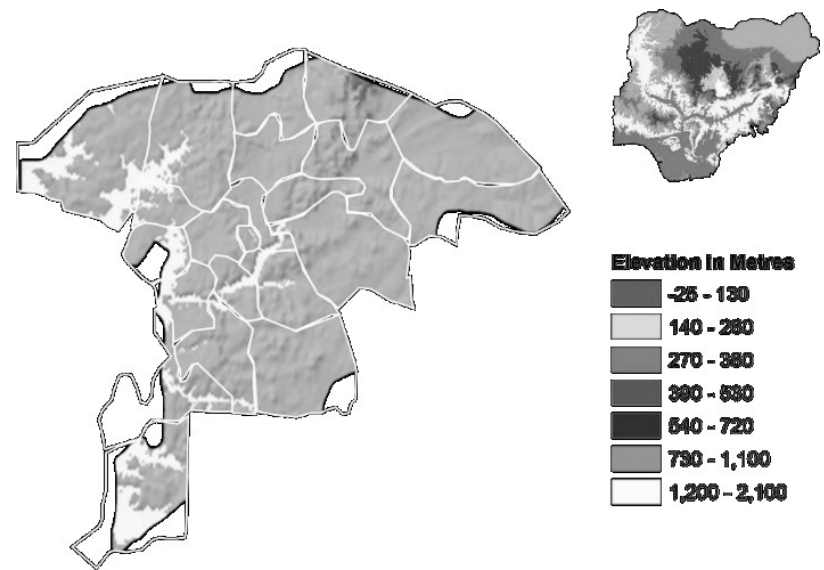

Figure 4. Elevation above Sea-level

\section{Summary}

Location

Population

Farming as primary occupation

Arable Land

Average land holding

Average Net Farm Income/Ha

Very Poor

Poor

Non-Poor

Adult Literacy in English

Adult Literacy in any Language

Youth Literacy in English

Youth Literacy in any Language

Active Internet Subscription

Active Voice Subscription

\section{The Approach}

A deeper analysis of the situation described above will reveal substantial opportunities for positive improvement. This can however, happen only when we go beyond the traditional mandate of wealth redistribution. Investing in rural people is a long-term solution to so many of the problems we face today. Hunger, poverty, youth unemployment and forced migration - all have deep roots in rural areas; and all can be vastly improved through investing in small- scale agriculture and inclusive rural development. Research conducted by IFAD $13^{\circ} 05^{\prime} \mathrm{N}, 05^{\circ} 15^{\prime} \mathrm{E}$

5.7 million

$$
80 \%
$$
$>250,000 \mathrm{Ha}$

$<1 \mathrm{Ha}$

$<£ 100$

$17.89 \%$

$59.64 \%$

$22.47 \%$

$22.1 \%$

$77.4 \%$

$33.1 \%$

$81.8 \%$

$1,264,793$

$2,248,306$

has shown that in Sub-Saharan Africa, investment in agriculture is up to 11 times more effective in reducing extreme poverty than investment in any other sector.

Sozecom plans to increase the productivity, income and food security of smallholder farming families by introducing measures to conserve the environment and improve crop yields and income with a special emphasis on women, households headed by women and landless families. This can be achieved by encouraging the participation of local communities in agro- waqf initiatives, training local village communities to 
manage their own waqf farms, providing access to credit, agricultural inputs and land where possible. Sozecom has secured many farms for community waqf, planted thousands of economically valuable varieties of trees. Using these communal waqf farms as models, Sozecom hopes to encourage communities to diversify their farming enterprise, adopt global best practices and secure reliable access to market.

Sozecom similarly is pursuing policies and approaches that leads to greater financial inclusivity for the rural people. It plans to bridge the financial and digital divide between the rural and urban areas by utilizing it's exttensive district-wide volunteer networks, developing bilingual digital tools and by increasingly streamlining its operations toward data driven activities. This will require substantial adjustments to capabilities. A new website, bilingual apps, structuring vast amount of primary and secondary data, acquisition of hardware and training are expected to become mainstream before the end of this year. Another focal point is the emphasis attached to scientific research, information gathering and information dissemination in all activities. To that end, Sozecom has formed strategic collaboration with National Research Institutions, universities, corporate organizations and individual consultants. A notable example is the partnership with Nigerian Institute for Oil Palm Research which led to the development of date palm seedlings suitable for Sokoto state. So far over 12,000 seedlings were procured and plan for 2 million seedlings in the next two years finalized. These are meant for district level waqf farms. Similar plans for Cashew, Neem, Tamarind, Moringa and Mango are concluded and alrewady in the first stage of implementation.

\section{Structure}

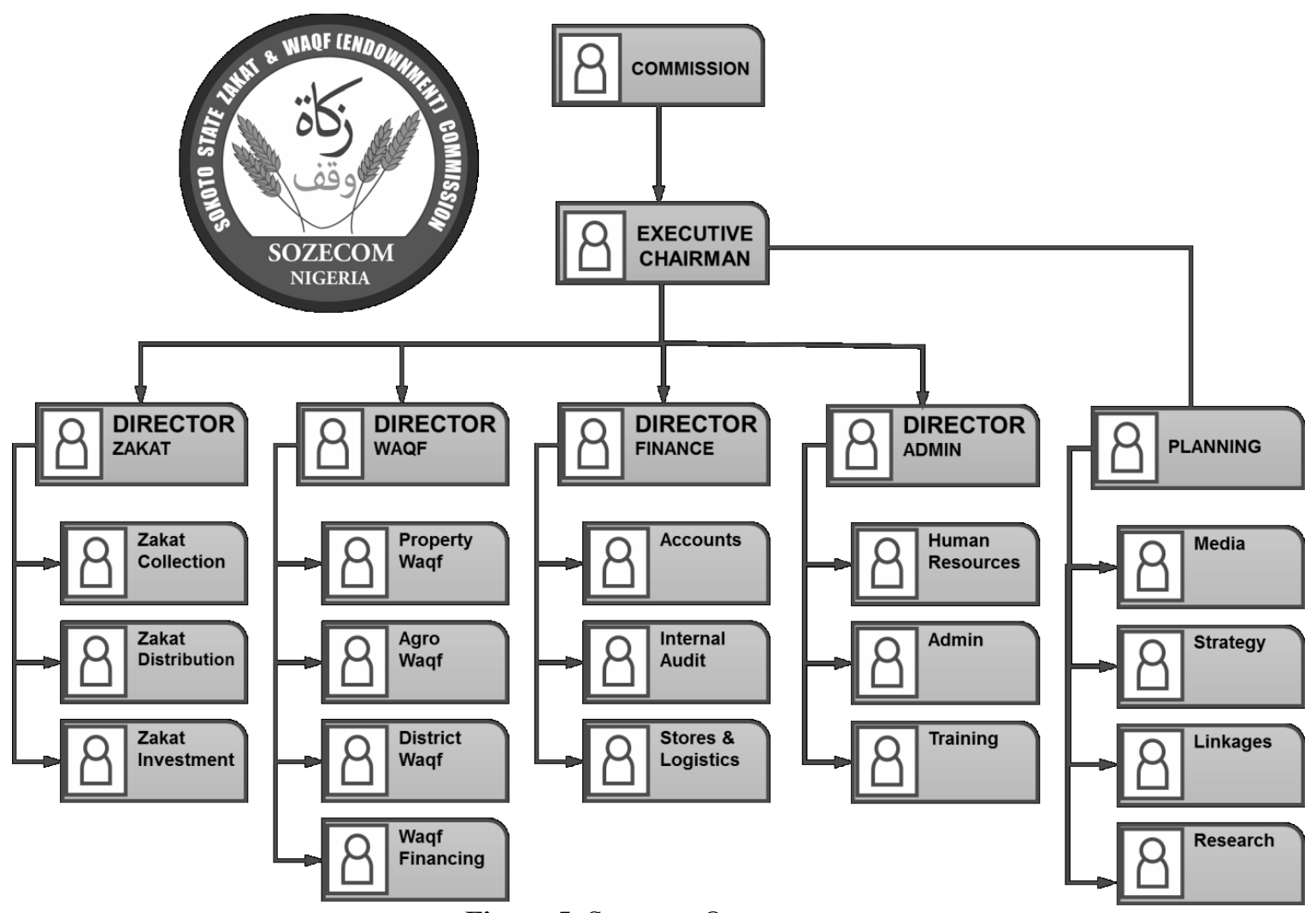

Figure 5. Sozecom Organogram 


\section{Funding}

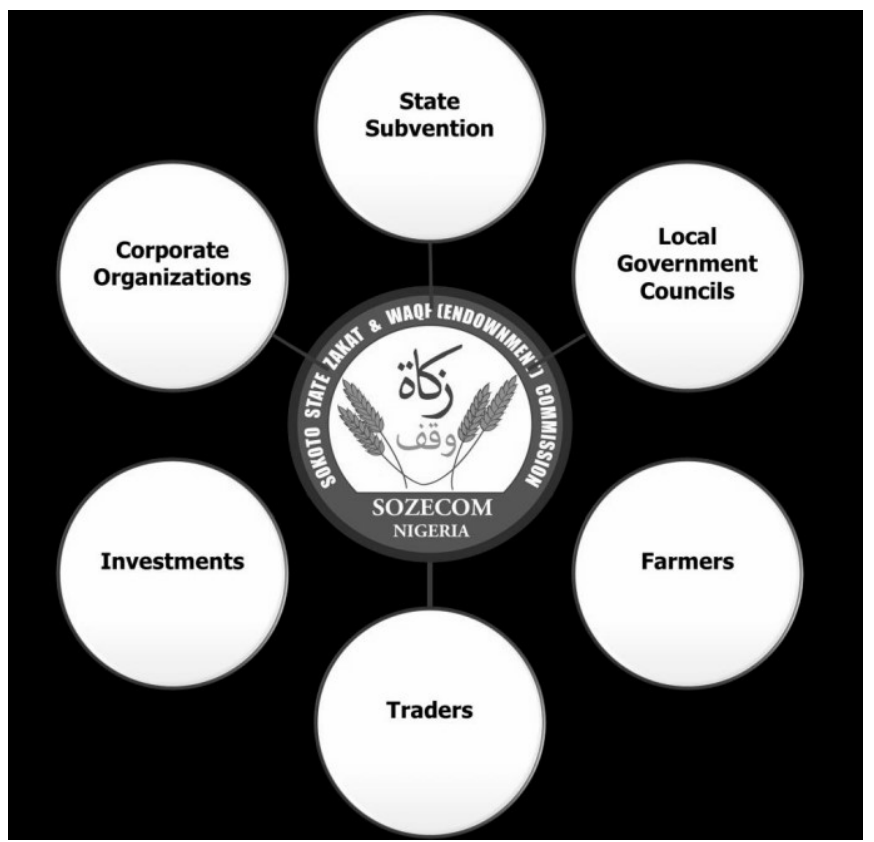

Figure 6. Sozecom Sources of Funding

The main sources of funding are monthly grants from the State and Local councils, Zakat payment by farmers, traders (in the form of cash, livestock and crops) and occasionally corporate organizations. Sozecom also invests in and own some corporate ventures. These funds are used for medical assistance, shelter, rehabilitation, emergency response, education, general welfare, ramadan package, addakly/qurbani and feeding of orphans, widows, poor, indebted, prisoners, disabled, elderly and the muállaf.

\section{Operations}

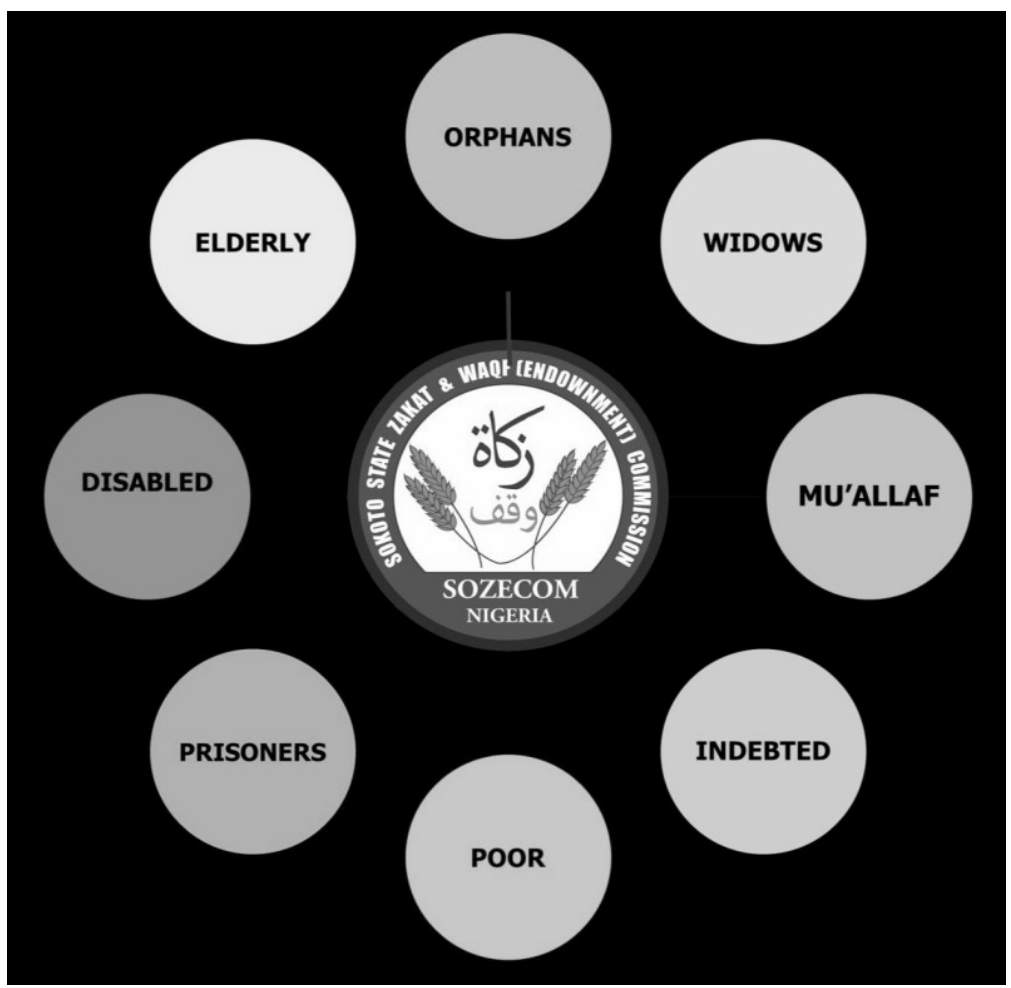

Figure 7. Sozecom Targetted Groups 


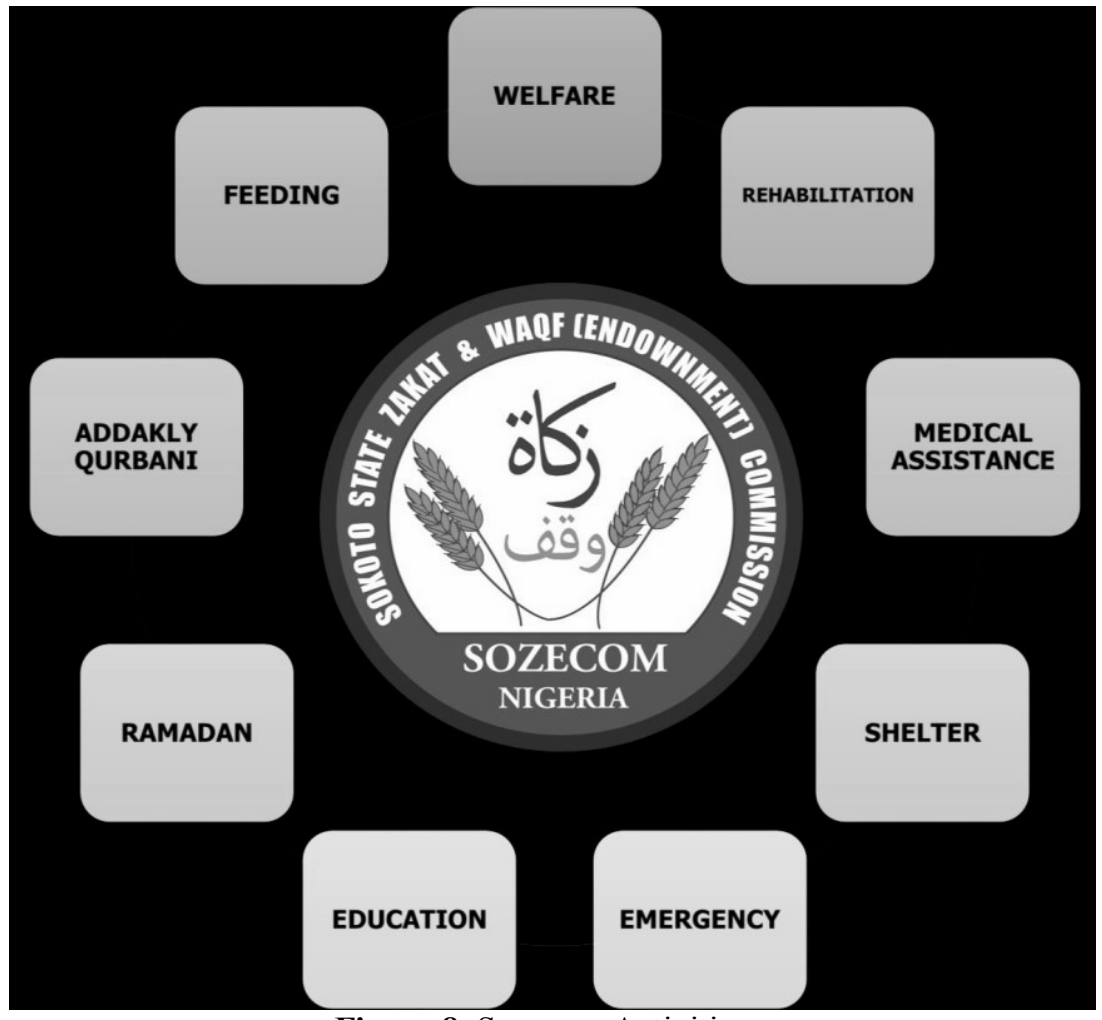

Figure 8. Sozecom Activities

Zakat Activities include collection, disbursement/distribution, sensitization and advocacy. Waqf spans, housing, commercial properties, conference halls, shops, supermarkets, hotels, student hostels, restaurants, farms, orchards and community school orchards managed by ZESVOC a statewide volunteer committee of students.

\section{Achievements}

From its humble beginning as a committee of few individuals, through recognition as a district zakat committee by government and as a legally established government commission, Sozecom has recorded many achievements. The entire milestone of Sozecom cannot be outlined here due to time limitation but notable success include:

- Institutionalizing Zakat issues into the mainstream priority area of government and society in the state from the hitherto almost forgotten pillar

- Creating a statewide Zakat infrastructure for collection, disbursement and management of funds covering the entire 23 Local Councils and 86 districts of the state

- Advocating and enactment of zakat laws in to the legal statute of the state

- Collection and disbursement of over 3 billion Naira to the needy recipients in the state and as far as Borno state in response to humanitarian crises there

- Securing of community waqf lands in many districts of the state, assets and businesses

- Establishing school waqf committees and waqf farms in all secondary schools in the state to help raise a generation of citizens engaged in this important sunnah and foundation for a sustainable economy

- Procurement and development of tens of thousands economic trees

- Strategic collaborations with numerous research, educational, governmental and financial institutions within and outside Nigeria, and

- Helping tens of thousands of needy people directly and securing access to intervention windows 


\section{CONCLUSION}

All the achievements outlined above where however made under an atmosphere of challenges. Sozecom like any regional charity organization faces the general challenges illustrated below Specific challenges include funding, technology and capacity. Funding by government competes with other urgent needs of the society. In that respect the state government tried to do its best in the face of dwindling revenue, rising cost and recurring humanitarian disasters. Sozecom's long term vision incorporates gradual financial autonomy by investment, using technology for zakat collection and endowments and by prudent use of resources. Technological capabilities to harness the potentials of digital tools also represent another challenge. Current workforce is limited by number due to existing limitations and affects the extent to which Sozecom achieves greater operational dexterity. The roll-out of mobile finance to rural areas inevitably encounters certain barriers such as illiteracy, financial illiteracy, digital illiteracy and lack of trust and limited agent/network coverage. Like all great opportunities, digital finance also comes with risks. What makes online financial systems easy to use for customers also makes them susceptible to cybercrime. The entry of nontraditional players poses new challenges for policy, regulation, and supervision. And the ease of transferring funds across the globe-often anonymously, using means such as cryptocurrencies-might increase illicit financial flows.

\section{REFERENCES}

[1] Digital Finance for Development, USAID, 2017

[2] Financial Inclusion Report, World Bank Group, 2016

[3] High-Level Principles for Digital Financial Inclusion, G20, 2016

Muhammad Lawal Maidoki

Sokoto State Zakat and Waqf (Endowment)

Commission

Sokoto, Nigeria

Sozecom.Zakat@gmail.com 